\section{Application of MS score in macrophage activation syndrome patients associated with adult onset Still's disease}

We read with great interest the article by Minoia et al which named development and initial validation of the macrophage activation syndrome (MAS)/systemic juvenile idiopathic arthritis (sJIA) (MS) score for diagnosis of MAS in sJIA.

MAS is a life-threatening complication of rheumatic disorders, including sJIA, adult-onset Still's disease (AOSD) and lupus. ${ }^{1-4}$ Timely diagnosis and appropriate treatment of MAS are particularly important to improve the prognosis of MAS patients. At present, hemophagocytic lymphohistiocytosis (HLH)-2004 and HLH-2009 criteria are widely used to identify MAS associated with AOSD. Hemophagocytic syndrome diagnostic (HS) score was developed previously to facilitate MAS recognition, but still requires validation. ${ }^{5}$ In 2019, Francesca Minoia et al reported a MS score for classification of sJIA-associated MAS patients. ${ }^{6}$ Considering that SJIA and AOSD are thought to constitute the same disease entity occurring at different ages, we intended to evaluate the application of MS score in AOSD-associated MAS patients.

We collected AOSD patients from 1 January 2012 to 31 July 2019 from six centres across China. Patients were included in this study if they were older than 18 years of age, and met the Yamagishi criteria for a diagnosis of AOSD. MAS was diagnosed using the HLH-2004 diagnostic criteria, and the diagnosis was confirmed by the attending rheumatologists. Clinical information was recorded and analysed. MS score was calculated for each patient according to the previous report.

A total of 450 AOSD patients (60 AOSD associated MAS, 390 AOSD without MAS) were included in this study. Clinical features and lab results as the time of MAS diagnosis were shown in table 1 . The application of the MS score $(\geq-2.1)$ yielded a sensitivity of $100 \%$, a specificity of $29.85 \%$, a positive predictive rate of $36.15 \%$, a negative predictive rate of $100 \%$ in the diagnosis of AOSD-MAS with a Kappa value of 0.320 . However, a further receiver operator characteristic curve analysis suggested

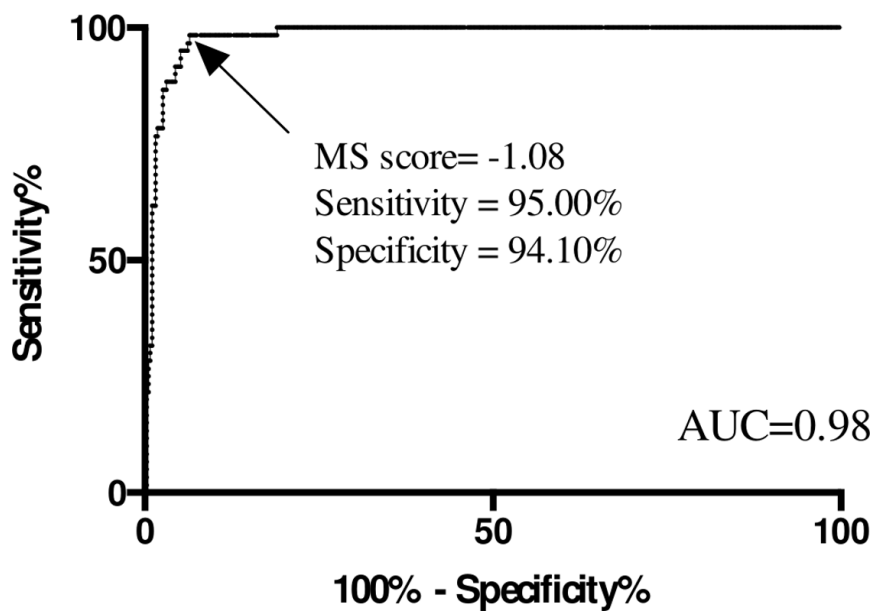

Figure 1 Modified criteria of MS score in the diagnosis of AOSD associated MAS. In a febrile patient with AOSD, the diagnosis of MAS should be considered if the MS score is $\geq-1.08$. The area under the curve (AUC) of the model is 0.98 . AOSD, adult-onset Still's disease; MAS, macrophage activation syndrome.

that setting -1.08 as the score cut-off could provide the best discrimination between AOSD with and without MAS (figure 1). MS score $\geq-1.08$ yielded a sensitivity of $94.10 \%$, a specificity of $95.00 \%$ in the diagnosis of MAS associated with AOSD. The positive predictive rate was $99.19 \%$ and the negative predictive rate of $71.25 \%$, with a Kappa value of 0.781 .

The current finding suggested that even though there are many similarities between SJIA and AOSD, adult and young patients have notable differences in terms of clinical manifestations and lab results. For instance, central nervous involvement is quite rare in AOSD-MAS patients, probably because adults usually have much more stable central nervous system. In addition, the levels of platelet count and fibrinogen are usually lower in AOSD-MAS patients as compared with those in sJIA-MAS patients, which could lead to higher MS scores in AOSD patients. Therefore, the items calculated in the reported sJIA-MS score as well as

Table 1 Clinical manifestations of AOSD patients with and without MAS

\begin{tabular}{|c|c|c|c|}
\hline & $\begin{array}{l}\text { AOSD with MAS } \\
(60)\end{array}$ & AOSD without MAS (390) & $P$ value \\
\hline Sex (male/female ) & $18 / 42$ & $72 / 318$ & 0.055 \\
\hline Age (years) & $29(22-37)$ & $38(27-50)$ & $<0.0001$ \\
\hline Death $(n, \%)$ & $13(21.67 \%)$ & $8(2.05 \%)$ & $<0.0001$ \\
\hline Fever $(n, \%)$ & $60(100 \%)$ & $255(65.38 \%)$ & $<0.0001$ \\
\hline Active arthritis (n, \%) & $19(31.67 \%)$ & $372(95.38 \%)$ & $<0.0001$ \\
\hline Splenomegaly & $50(83.33 \%)$ & $52(13.33 \%)$ & $<0.0001$ \\
\hline Central nervous system disease & $1(1.67 \%)$ & 0 & 0.133 \\
\hline Haemorrhagic manifestations & $1(1.67 \%)$ & $3(0.77 \%)$ & 0.437 \\
\hline Platelet count $\left(\times 10^{9} / \mathrm{L}\right)$ & $90(60-144)$ & $244(222-485)$ & $<0.0001$ \\
\hline Liver dysfunction (n, \%) & $58(96.67 \%)$ & $73(18.72 \%)$ & $<0.0001$ \\
\hline Lactic dehydrogenase (U/L) & 1024 (599-2145) & $313(222-485)$ & $<0.0001$ \\
\hline Triglycerides (mmol/L) & $2.35(1.82-3.78)$ & $1.42(0.97-2.03)$ & $<0.0001$ \\
\hline Fibrinogen (mg/dL) & $151(104-219)$ & $306(52-452)$ & $<0.0001$ \\
\hline Ferritin $(\mathrm{ng} / \mathrm{mL})^{*}$ & $1500(1500-1500)$ & $1264(359-1500)$ & $<0.0001$ \\
\hline Bone marrow hemophagocytosis ( $n, \%)$ & $39(65 \%)$ & $13(3.33 \%)$ & $<0.0001$ \\
\hline MS score (median) & $-0.01(-0.27$ to 0.50$)$ & $-2.67(-3.51$ to 1.82$)$ & $<0.0001$ \\
\hline
\end{tabular}

* The up limit of the detection of ferritin was $1500 \mathrm{ng} / \mathrm{mL}$ in our centres.

AOSD, adult-onset Still's disease; MAS, macrophage activation syndrome. 
the cut-off for sJIA-MAS diagnosis $(>-2.1)$ should be modified for diagnosis of MAS associated with AOSD. In our cohort, MS score $\geq-1.08$ might be a better cut-off for AOSD-MAS diagnosis with an area under the curve of 0.98 .

Further prospective and independent validations with larger sample size are needed to evaluate the modified MS score in the diagnosis for the life-threatening MAS condition in AOSD patients.

\section{Ran Wang $\odot,{ }^{1}$ Ting Li, ${ }^{2}$ Shuang Ye, ${ }^{2}$ Wenefng Tan, ${ }^{3}$ Cheng Zhao, ${ }^{4}$ Yisha Li, ${ }^{5}$ Chunde Bao $\odot{ }^{1}$ Qiong Fu ${ }^{1}$}

1 Department of Rheumatology, Shanghai Jiao Tong University School of Medicine Affiliated Renji Hospital, Shanghai, China

2Department of Rheumatology, Shanghai Jiao Tong University School of Medicine Affiliated Renji Hospital South Campus, Shanghai, China

${ }^{3}$ Department of Rheumatology, The First Affiliate Hospital of Nanjing Medical University, Nanjing, China

${ }^{4}$ Department of Rheumatology, The Affiliated Nanjing Drum Tower Hospital of Nanjing University Medical School, Nanjing, China

${ }^{5}$ Department of Rheumatology, Xiangya Hospital of Central South University, Changsha, China

Correspondence to Dr Qiong Fu, Department of Rheumatology, Shanghai Jiao Tong University School of Medicine, Affiliated Renji Hospital, Shanghai, China; fuqiong5@163.com

Correction notice This article has been corrected since it published Online First. The correspondence author details have been corrected.

Handling editor Josef Smolen

Funding This study was funded by Science and Technology Commission of Shanghai Municipality.

Competing interests None declared.

Patient consent for publication Not required.

Provenance and peer review Not commissioned; internally peer reviewed.
(C) Author(s) (or their employer(s)) 2021. No commercial re-use. See rights and permissions. Published by BMJ.

RW and TL contributed equally.

$$
\text { A) Check for updates }
$$

To cite Wang R, Li T, Ye S, et al. Ann Rheum Dis 2021;80:e145.

Received 8 September 2019

Accepted 12 September 2019

Published Online First 14 October 2019

\section{SLinked}

http://dx.doi.org/10.1136/annrheumdis-2019-216310

Ann Rheum Dis 2021:80:e145. doi:10.1136/annrheumdis-2019-216286

\section{ORCID iDs}

Ran Wang http://orcid.org/0000-0001-7857-8433

Chunde Bao http://orcid.org/0000-0002-0466-1872

\section{REFERENCES}

1 Siddiqui M, Putman MS, Dua AB. Adult-Onset still's disease: current challenges and future prospects. Open Access Rheumatol 2016;8:17-22.

2 Bracaglia C, Prencipe G, De Benedetti F. Macrophage activation syndrome: different mechanisms leading to a one clinical syndrome. Pediatr Rheumatol Online J 2017:15.

3 Guilpain P, Le Quellec A. About the complexity of adult onset still's disease... and advances still required for its management. BMC Med 2017;15:5.

4 Parisi F, Paglionico A, Varriano V, et al. Refractory adult-onset still disease complicated by macrophage activation syndrome and acute myocarditis. Medicine 2017:96:e6656.

5 Fardet L, Galicier L, Lambotte O, et al. Development and validation of the HScore, a score for the diagnosis of reactive hemophagocytic syndrome. Arthritis Rheumatol 2014;66:2613-20.

6 Minoia F, Bovis F, Davi S, et al. Development and initial validation of the MS score for diagnosis of macrophage activation syndrome in systemic juvenile idiopathic arthritis. Ann Rheum Dis 2019:78:1357-62. 